\title{
SISTEM DAN MANAJEMEN SKRIPSI PROGRAM STUDI TEKNIK GEOLOGI UPN “VETERAN” YOGYAKARTA BERBASIS WEBSITE
}

\author{
Muchamad Ocky Bayu Nugroho (1), Basuki Rahmad (2), Muhamad Imam AI Fatah (3), \\ Rahmat Aziz AL Hakim(4) \\ 1,2Departemen Teknik Geologi, Fakultas Teknologi Mineral, Universitas Pembangunan Nasional \\ "Veteran" Yogyakarta \\ 3,4Departemen Teknik Informatika, Fakultas Teknologi Industri, Universitas Pembangunan \\ Nasional "Veteran" Yogyakarta \\ JI. SWK 104 Lingkar Utara Ring Road Condong Catur, Sleman, Yogyakarta \\ e-mail : bayu.ocky@gmail.com ${ }^{(1)}$
}

\begin{abstract}
The thesis registration was still manually causes a lot of problem in administration process that impacted to lecturers and students due to universities regulation. The impacts for lecturer are students supervisor not evenly well distribued, not well connected between the specialization of lecturers and the students thesis's topic and still difficult to monitoring students thesis progress at the same time, the impact for students is difficult to meet the coordinator. Manajement system based on website is solution to solve that problem using several function such as limitation for thesis supervisor, monitoring student's progess and choosing any topic with any lecturer's competency independently. The research and system development were the methods to build the system. Research method incuding observation, interview, collecting support data and for developing main system using Waterfall method. The primary data (observation, interview, etc.) have been analyzed and tested using waterfall method until to be perfect system. The system was covered in the website that could be accessed by students, lecturers and admins. The final website has been succesfully tested in to several web browser and proven gave the simple and well organized thesis administration processes based on student and lectures correspodencies.
\end{abstract}

\section{Keywords : Thesis, Administration, Website, Information, System}

\begin{abstract}
Abstrak
Proses pendaftaran skripsi yang masih manual menimbulkan banyak permasalahan yang terjadi saat proses administrasi yang berdampak kepada dosen dan mahasiswa karena aturan dari Universitas. Dampak kepada dosen antara lain adalah tidak meratannya pembagian dosen pembimbing atau pembahas, tidak kesesuaian bidang keahlian dosen dengan topik skripsi dan sulitnya memantau mahasiswa bimbingan, sedangkan dampak untuk mahasiswa adalah sulitnya menemui koordinator skripsi. Sistem manajemen skripsi berbasis website adalah solusi untuk mengatasi hal tersebut dengan menjalankan beberapa fungsi seperti pembatasan jumlah kuota tiap pembimbing, laporan administrasi skripsi, pemantauan mahasiswa yang sedang mengambil skripsi dan pemilihan dosen sesuai topik dan kompetensi secara independen oleh mahasiswa. Penelitian dan pengembangan sistem adalah metode yang digunakan untuk membangun sistem. Metode penelitian meliputi observasi, wawancara, dan pengumpulan data pendudukung, sedangkan metode pengembangan sistem menggunakan metode Waterfall. Data primer (observasi, wawancara, dll) telah dianalisis dan diuji menggunakan metodel Waterfall hingga menjadi sistem yang sempurna. Sistem sudah terkover dalam website yang dapat diakses oleh mahasiswa, dosen dan admin. Website telah sukses diujikan dengan beberapa web browser dan terbukti memberikan proses administrasi yang simpel dan terorganisir baik berdasarkan hasil korespondensi mahasiswa dan dosen.
\end{abstract}

Kata Kunci : Skripsi, Administrasi, Website, Informasi, Sistem

\section{PENDAHULUAN}

Tugas Akhir atau skripsi adalah karya ilmiah yang disusun oleh mahasiswa setiap program studi berdasarkan hasil penelitian suatu masalah yang dilakukan secara seksama dengan bimbingan dosen pembimbing. Tugas akhir merupakan salah satu persyaratan kelulusan mahasiswa. Ketentuan-ketentuan mengenai tugas akhir diatur oleh masing-masing fakultas, dengan 
mengikuti standar universitas (UNY, 2020). Banyak mahasiswa menganggap tugas akhir sebagai beban yang amat berat diakibatkan banyak hal yang harus dipersiapkan dalam pengerjaannya, mulai dari sampel untuk penelitian, observasi data ke berbagai tempat yang diperlukan, analisa data yang sudah didapatkan dan banyak hal lainnya. Salah satu hal yang amat penting bagi mahasiswa sebelum mengerjakan tugas akhir adalah melakukan administrasi ke birokrasi jurusan sebagai bukti bahwa mahasiswa yang bersangkutan benar-benar akan menjalani atau mengerjakan tugas akhir sesuai dengan yang diajukan.

Permasalahan dalam manajemen dan pengambilan skripsi di Prodi Teknik Geologi UPN "Veteran" Yogyakarta ada beberapa antara lain adalah metode administrasi yang masih manual dengan mengisi form dan buku rekapan yang sangat memerlukan waktu lama dalam proses dan tahapan, sistem kuota tiap-tiap pembimbing dan pembahas yang sudah ditentukan oleh universitas belum dapat di terapkan dengan baik yang berakibat membutuhkan usaha lebih. Pada lain hal proses pemantauan mahasiswa yang sedang menjalani skripsi oleh dosen dan koordinator belum berjalan baik sehingga berdampak pada waktu kelulusan yang terlambat.

Atas dasar beberapa masalah tersebut, Prodi Teknik Geologi UPN "Veteran" Yogyakarta berinisiatif untuk mengubah metode administrasi yang masih manual menjadi metode online sehingga setiap mahasiswa dapat melakukan administrasi pendaftaran skripsi langsung menggunakan device yang dimiliki seperti smartphone ataupun laptop dan didukung dengan teknologi internet. Teknik Geologi UPN "Veteran" Yogyakarta dalam hal ini merancang sebuah website yang terdapat sistem terintegrasi didalamnya dan dapat diakses setiap mahasiswa ataupun dosen dimanapun tanpa harus ke kampus saat pendaftaran tugas akhir dan pengawasan bimbingan.

\section{LANDASAN TEORI}

\section{Framework}

Framework adalah koleksi atau kumpulan potongan-potongan program yang disusun atau diorganisasikan sedemikian rupa, sehingga dapat digunakan untuk membantu membuat aplikasi utuh tanpa harus membuat semua kodenya dari awal (Hakim, 2010:3). Framework memberikan struktur dasar dalam membangun web sehingga dapat lebih cepat, stabil dan dalam pengkoreksiannya mudah ditemukan.

\section{Codeigniter}

Codeigniter adalah sebuah framework PHP yang dapat membantu mempercepat developer dalam pengembangan aplikasi web berbasis PHP dibanding jika menulis semua kode program dari awal (Hakim, 2010). Karena website ini berdasar akun shared hosting dan akan dikembangkan berisi video tutorial dan user guide maka framework PHP dirasa tepat.

\section{PHP (PHP Hypertext Preprocessor)}

PHP adalah bahasa server-side-scripting yang menyatu dengan HTML untuk membuat halaman web yang dinamis (Arief, 2011). Website ini merupakan website dinamis karena dibutuhkan pengisian form dan data manajemen sehingga sangat tepat menggunakan PHP.

\section{Bootstrap}

Bootstrap merupakan framework untuk membangun desain web secara responsif (Husein Alatas, 2013). Artinya, tampilan web yang dibuat oleh bootstrap akan menyesuaikan ukuran layar dan browser yang kita gunakan baik di desktop, tablet ataupun mobile device. Sangat cocok untuk website ini yang diakses oleh banyak orang dan bersifat web dinamis.

\section{HTML (Hyper Text Markup Language)}

HTML adalah bahasa yang digunakan pada dokumen web sebagai bahasa untuk pertukaran dokumen web". Dokumen HTML terdiri dari komponen yaitu tag, elemen dan atribut. Tag adalah tanda awal < dan tanda akhir > yang digunakan sebagai pengapit suatu elemen. Elemen adalah nama penanda yang diapit oleh tag yang memiliki fungsi dan tujuan tertentu pada dokumen HTML. Elemen dapat memiliki elemen anak dan juga nilai. Elemen anak adalah suatu elemen yang berada didalam elemen pembuka dan elemen penutup induknya. Nilai yang dimaksud 
adalah suatu teks atau karakter yang berada diantara elemen pembuka dan elemen penutup. Atribut adalah properti elemen yang digunakan untuk mengkhususkan suatu elemen. Elemen dapat memiliki atribut yang berbeda pada tiap masing-masingnya (Sibero, 2013).

\section{CSS (Cascading Style Sheet)}

CSS merupakan sebuah bahasa yang menjelaskan presentasi dari elemen konten yang terdapat di HTML. Style Sheets memberikan serangkaian aturan dalam menghias dokumen dengan memberikan desain ke beberapa konten yang ada (Casciano, 2010).

\section{JavaScript}

JavaScript adalah suatu bahasa pemrograman yang dikembangkan untuk dapat berjalan pada web browser (Sibero, 2013), dengan kata lain JavaScript adalah bahasa pemrograman untuk memberikan kemampuan tambahan ke dalam bahasa pemrograman HTML (Hypertext Markup Language).

\section{MySQL}

MySQL adalah salah satu jenis database server yang sangat terkenal dan banyak digunakan untuk membangun aplikasi web yang menggunakan database sebagai sumber dan pengolahan datanya (Arief, 2011). Kelebihan dari MySQL adalah gratis, handal, selalu di-update dan banyak forum yang memfasilitasi pengguna jika memiliki kendala. MySQL juga sering di bundling dengan web server sehingga proses instalasinya menjadi lebih mudah.

\section{Unified Modelling Language (UML)}

UML (Unified Modeling Language) adalah bahasa pemodelan untuk sistem atau perangkat lunak yang berparadigma (berorientasi objek)." Pemodelan (modeling) sesungguhnya digunakan untuk penyederhanaan permasalahan-permasalahan yang kompleks sedemikian rupa sehingga lebih mudah dipelajari dan dipahami (Nugroho, 2009). Bahasa ini digunakan karena dalam website ini banyak menggunakan pemodelan dengan tahapan lebih dari satu.

\section{Model Waterfall}

Model waterfall adalah model yang paling banyak digunakan untuk tahap pengembangan. Model waterfall ini juga dikenal dengan nama model tradisional atau model klasik. Model air terjun (waterfall) sering juga disebut model sekuensial linier (squential linear) atau alur hidup klasik (Classic cycle)". Model air terjun ini menyediakan pendekatan alur hidup perangkat lunak secara sekuensial terurut dimulai dari analisis, desain, pengkodean, pengujian dan tahap pendukung (support). Website dan sistem harus melalui semua tahap dengan maksud untuk mengetahui sumber masalah dan koreksi sebelum web atau sistem diluncurkan.

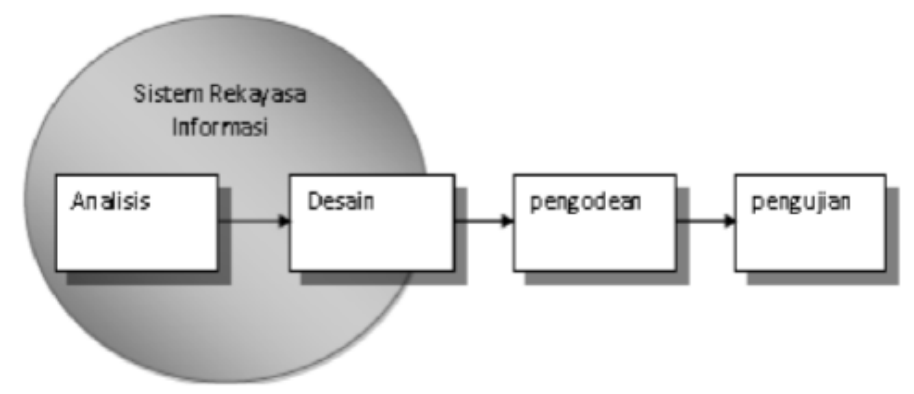

Gambar 1. Metode Waterfall (Sumber : Rahmayu, 2016)

\section{METODOLOGI PENELITIAN}

\section{Data Penelitian}

Merupakan data primer dan data sekunder dimana data primer berasal dari observasi dan wawancara dari dosen dan pembimbing tentang kondisi pelayanan komisi tugas akhir, sedangkan data sekunder merupakan data pendukung yang berupa SOP mekanisme pendaftaran tugas akhir, data dosen dan mahasiswa yang sudah terdaftar sebelumnya selama 2 semester terakhir dan literatur atau publikasi. 
Teknik Pengambilan Data

1. Observasi adalah melakukan pengamatan dari proses yang sudah berjalan sebelumnya apa, kenapa dan bagaimana proses berjalan.

2. Wawancara yang dilakukan peneliti kepada mahasiswa (perwakilan setiap angkatan), dosen (perwakilan) dan koordinator skripsi terkait proses dan manjamen selama paling sedikit satu semester sebelumnya.

3. Mengumplkan data-data pendudukung seperti SOP dan mekanisme pendaftaran tugas akhir yang ada sebelumnya, data mahasiswa yang sedang menempuh skripsi, format administrasi dari bagian urusan skripsi (STU Kolokium) dan syarat dan peraturan mahasiswa untuk mengajukan atau mengambil skripsi.

4. Studi referensi atau literatur

Semua data yang dikumpulkan akan diolah dan menjadi dasar dalam pembuatan sistem dan website

\section{Alat yang Digunakan}

Kebutuhan perangkat lunak dan perangkat keras merupakan kebutuhan yang dibutuhkan untuk melakukan pengerjaan dalam processing system untuk mendukung bekerjanya sistem ini. Adapun perangkat lunak dan perangkat keras yang dibutuhkan seperti pada Tabel 1 dan Tabel 2.

Tabel 1. Tabel Kebutuhan Perangkat Lunak

\begin{tabular}{|l|l|l|}
\hline No & \multicolumn{1}{|c|}{ Jenis Software } & \multicolumn{1}{c|}{ Nama Software } \\
\hline 1 & Sistem Operasi & Windows 10 Pro 64-bit dan Ubuntu 16.4 \\
\hline 2 & Editor Text & Visual Studio Code \\
\hline 3 & Database dan Web Server & $\begin{array}{l}\text { XAMPP yang di dalamnya sudah termasuk } \\
\text { basis data MySQL dan Web Server Apache }\end{array}$ \\
\hline 4 & Bahasa Pemrograman & PHP dan Javascript \\
\hline 5 & Web Browser & Mozilla Firefox dan Google Chrome \\
\hline 6 & Editor Gambar & Corel Draw \\
\hline
\end{tabular}

Tabel 2. Tabel Kebutuhan Perangkat Keras

\begin{tabular}{|l|l|}
\hline No & \multicolumn{1}{|c|}{ Jenis Perangkat Keras } \\
\hline 1 & $\begin{array}{l}\text { Komputer / Laptop dengan processor Intel Pentium, } \\
\text { processor minimal 1.6 GHz atau lebih tinggi }\end{array}$ \\
\hline 2 & RAM 2 MB atau lebih tinggi \\
\hline 3 & VGA minimal 128 MB atau lebih \\
\hline
\end{tabular}

\section{HASIL DAN PEMBAHASAN}

\section{Perancangan Sistem}

Use Case Diagram adalah pemodelan untuk menggambarkan kelakuan (behavior) sistem yang akan dibuat. Diagram use case digunakan untuk mengetahui fungsi apa saja yang ada di dalam sebuah sistem dan siapa saja yang berhak menggunakan fungsi-fungsi tersebut. Penekanan pada diagram ini adalah "apa" yang diperbuat sistem, dan bukan "bagaimana". Adapun Use Case Diagram dari sistem yang ditunjukan oleh Gambar 2.

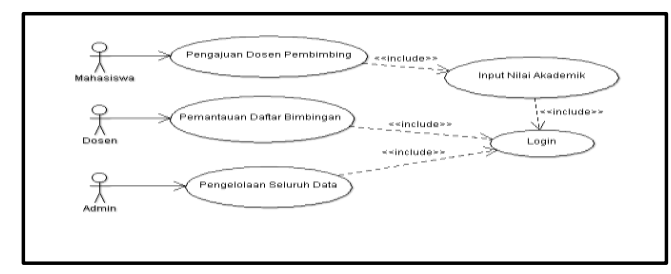

Gambar 2. Use Case Diagram 
Perancangan Metode Waterfall

Analisis

Berdasarkan data-data yang telah dikumpulkan, peneliti dapat mengetahui permasalahanpermasalahan yang terdapat di sistem tersebut. Permasalahan-permasalahan yang terdapat di sistem yang sudah ada yakni proses administrasi akan memerlukan waktu yang lama, sistem kuota tiap-tiap pembimbing, pembahas yang sudah ditentukan oleh Universitas dan Fakultas belum dapat di terapkan dengan baik yang berakibat membutuhkan usaha lebih dan proses pemantauan mahasiswa yang sedang menjalani skripsi oleh dosen dan koordinator belum berjalan baik sehingga berdampak pada waktu kelulusan yang terlambat.

\section{Desain}

Peneliti merancang antarmuka program menggunakan aplikasi Sublime Text sebagai text editor dengan menggunakan bahasa pemograman php. Peneliti merancang tampilan homepage admin master, tampilan kelola data mahasiswa admin master, tampilan kelola data dosen admin master, tampilan homepage dosen master, tampilan kelola data mahasiswa dosen master, tampilan homepage mahasiswa master, tampilan kelola data dosen mahasiswa master.

\section{Pembuatan Kode}

Peneliti menggunakan bahasa pemograman php dan html untuk menterjemahkan perancangan kedalam bentuk bahasa yang dimengerti komputer. Pembuatan kode di halaman antar muka dosen, admin dan mahasiswa untuk menampilkan data, form login dosen, form login mahasiswa dan form login admin. Pembuatan kode di halaman antar muka admin untuk menampilkan data dosen, data mahasiswa yang dapat mengambil skripsi, kuota, kelompok bidang keahlian dan pengelolaannya. Pembuatan kode di halaman antar muka dosen toko untuk mengelola data mahasiswa bimbingan. Pembuatan kode di halaman muka mahasiswa untuk mengetahui dan memilih data dosen sesuai bidang keahlian yang nantinya akan menjadi pilihan sesuai topik.

\section{Pengujian sistem}

Peneliti melakukan pengujian aplikasi dengan menggunakan 3 web browser yaitu: Google Chrome, Mozila Firefox, Internet Expolrer dan Apache sebagai servemya. Peneliti melakukan pengujian untuk 3 users yaitu :

1. Admin Login antara lain adalah halaman muka admin, halaman kelola data mahasiswa, halaman kelola data dosen, halaman kelola data bimbingan, halaman kelola data bidang keahlian, dan halaman kelola data bidang keahlian dosen.

2. Mahasiswa login antara lain halaman formulir nilai, halaman formulir bimbingan dan halaman untuk mengunduh lembar $\mathrm{A} 1, \mathrm{~A} 2$ dan $\mathrm{A} 3$.

3. Dosen login antara lain halaman beranda dosen dan status bimbingan mahasiswa.

Dengan melakukan pengujian, peneliti dapat menemukan kesalahan-kesalahan yang mungkin terjadi sehingga peneliti dapat melakukan perbaikan dan memastikan bahwa hasil yang di terapkan telah tercapai. Hasil penelitian merupakan suatu website yang tersimatis dan dapat diakses pada alamat www.komisiskripsitg.com dengan tujuan memecahakan permasalahan hasil analisa awal sebagai bentuk upaya perbaikan pelayanan dan kualitas di Prodi Teknik Geologi UPN "Veteran" Yogyakarta. Terdapat 3 users utama dalam website ini yaitu admin, dosen dan mahasiswa.

\section{Model Admin}

Admin berperan mengelola semua data. Pengelolaan data hanya dapat dilakukan setelah melakukan login. Pengelolaan tersebut seperti melihat, mengubah, membuat, dan menghapus data. Data yang diolah yaitu data admin, mahasiswa, dosen, bidang matakuliah, daftar bimbingan mahasiswa, dan kompetensi dosen. Terdapat juga tombol logout untuk keluar dari beranda admin. 


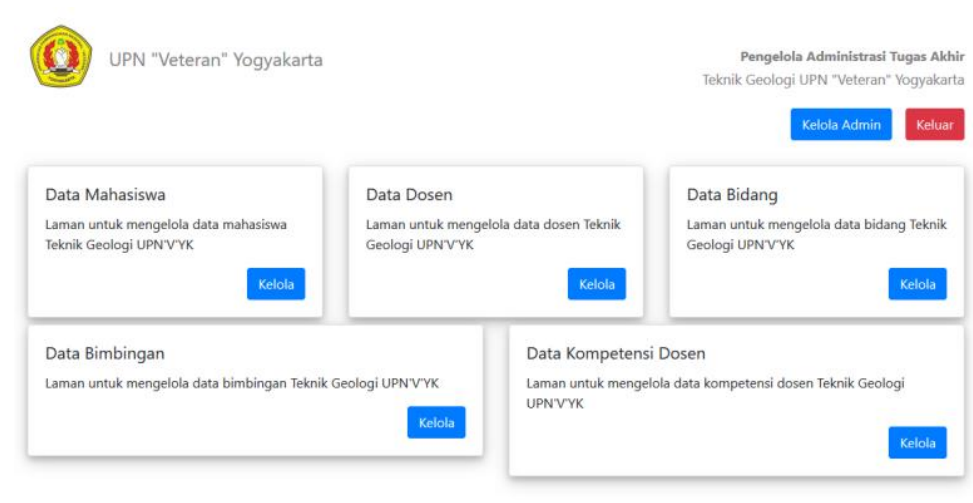

Gambar 3. Tampilan Beranda Admin

Merupakan tampilan beranda admin yang menunjukan admin/koordinator skripsi dapat mengubah atau mengelola data mahasiswa, dosen, bidang, bimbingan dan kompetensi dosen seperti yang ditunjukan Gambar 3

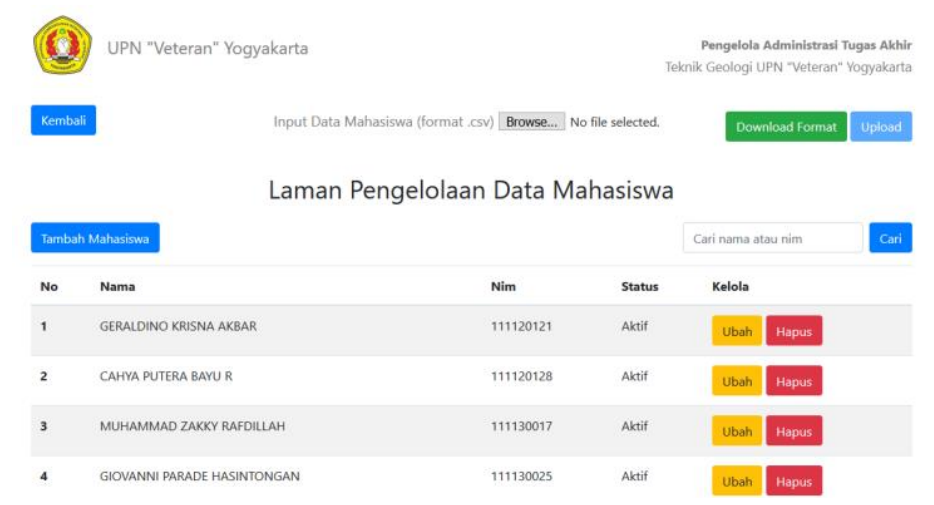

Gambar 4. Tampilan Kelola Mahasiswa oleh Admin

Kelola data mahasiswa adalah pekerjaan admin untuk menambahkan data mahasiswa yang sudah dapat mengambil skripsi setiap semester dan menghapus/ubah data jika ada kesalahan input atau mahasiswa sudah lulus seperti yang ditunjukan Gambar 4.

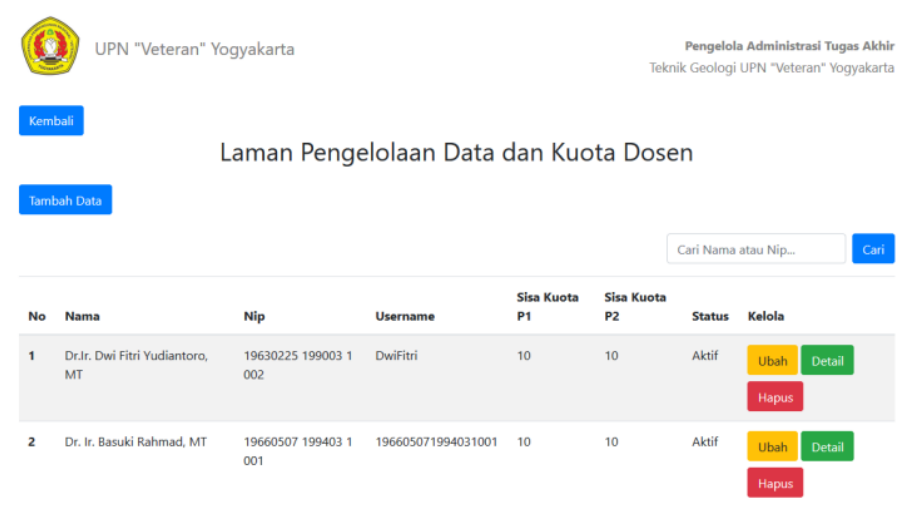

Gambar 5. Tampilan Kelola Dosen oleh Admin

Kelola data dosen untuk memantau dan memanajen kuota pembimbing dan memantau status dosen seperti yang ditunjukan Gambar 5. 


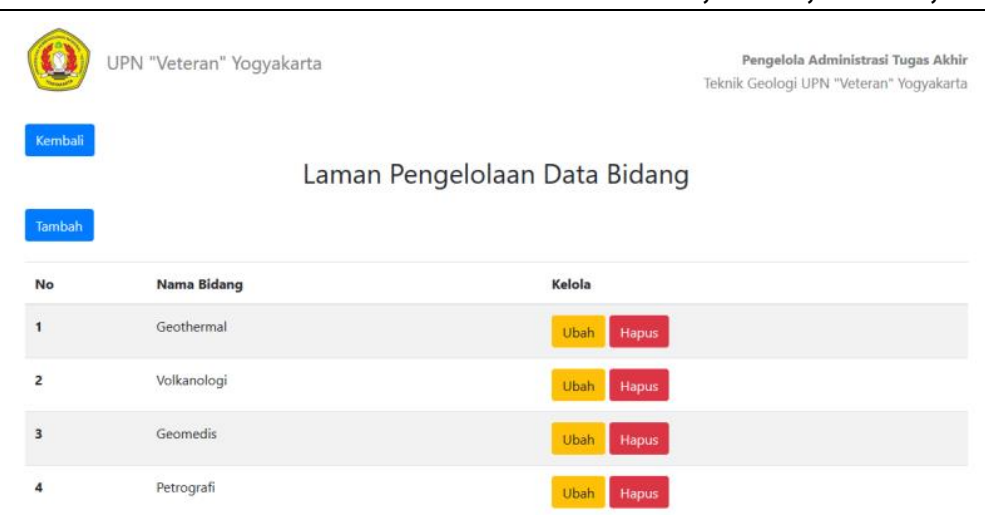

Gambar 6. Tampilan Kelola Bidang oleh Admin

Kelola data bidang merupakan pengelolaan data bidang ilmu atau sub ilmu dalam prodi teknik geologi yang nantinnya akan menjadi fokus kompetensi atau bidang keahlian dosen seperti yang ditunjukan Gambar 6.

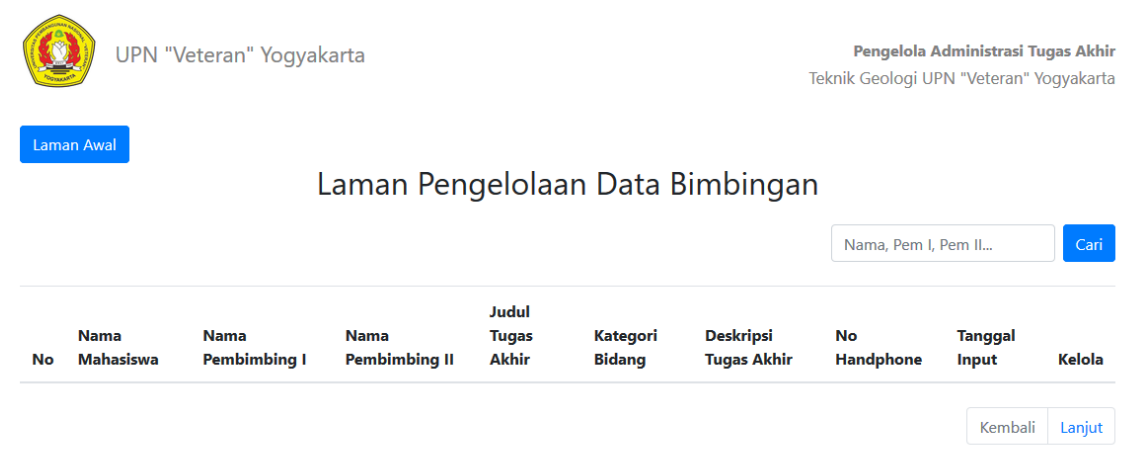

\section{Gambar 7. Tampilan Kelola Bimbingan oleh Admin}

Kelola data bimbingan merupakan pengelolaan data bimbingan skripsi mahasiswa oleh dosen sehingga dipantau progres, kuota, kesesuaian topik dan waktu pengambilan skripsi seperti yang ditunjukan Gambar 7.

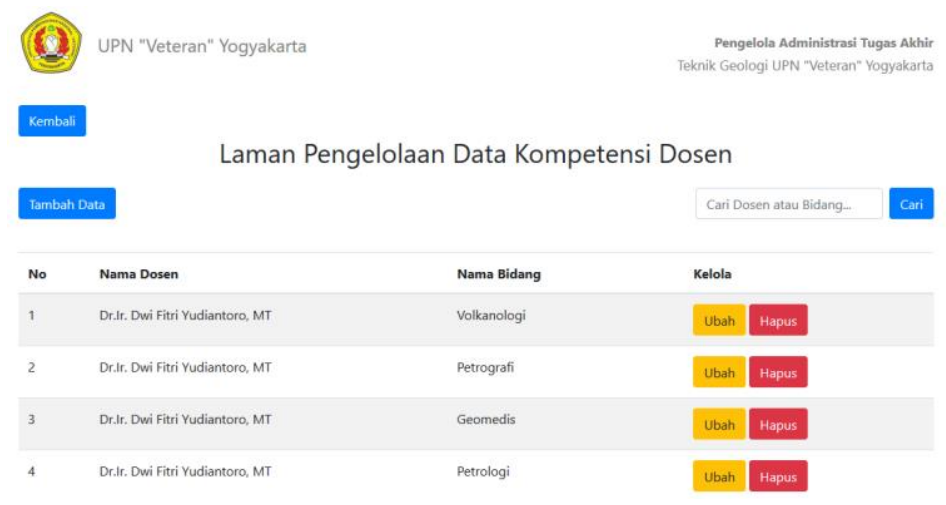

Gambar 8. Tampilan Kelola Kompetensi Dosen oleh Admin

Kelola data bimbingan merupakan pengelolaan kompetensi dosen yang nantinya akan disesuaikan oleh minat dan topik skripsi mahsiswa sebagai dosen pembimbingnya seperti yang ditunjukan Gambar 8. 


\section{Model Mahasiswa}

Mahasiswa berperan sebagai pelaku skripsi yang harus memenuhi syarat yang sudah ditentukan. Mahasiswa dapat memilih dosen pembimbing sesuai topik skripsi dan mengunduh 3 formulir untuk sebagai bukti dan nanti diserahkankan kepada koordinator.
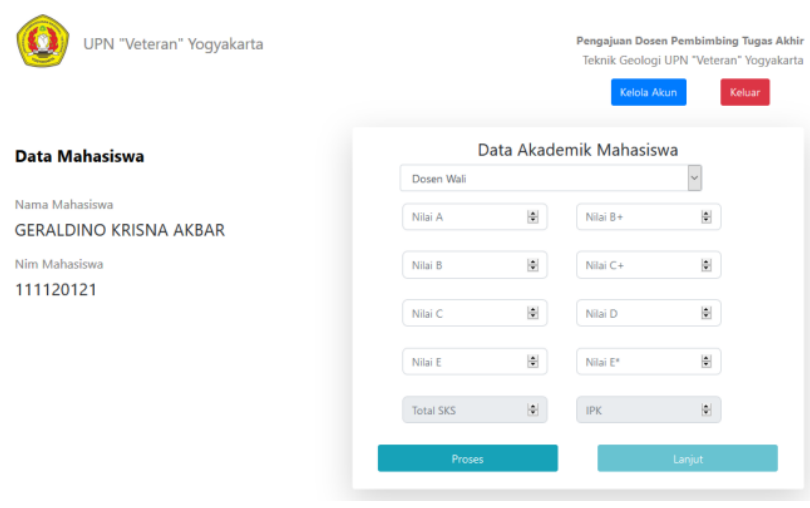

\section{Gambar 9. Tampilan Formulir Nilai Mahasiswa}

Sebelum melakukan input mahasiswa diharuskan mengisi nilai sesuai dengan transkrip terakhir dimana nilai ini nantinya akan menjadi isian dalam formulir yang diunduh untuk pendaftaran seperti yang ditunjukan Gambar 9. .
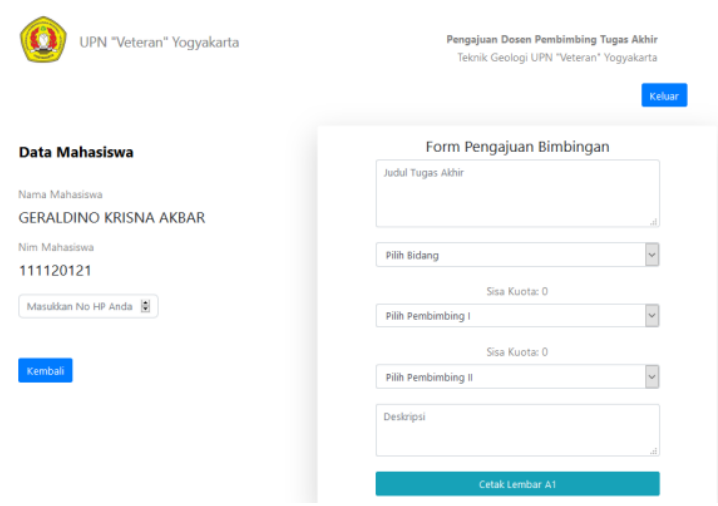

\section{Gambar 10 Tampilan Formulir Bimbingan Mahasiswa}

Mahasiswa melakukan pemilihan dosen berdasarkan topik yang tertuang pada judul rencana skripsi dan otomatis pemilihan pembimbing akan muncul dosen yang sesuai bidang keahliannya. seperti yang ditunjukan Gambar 10. Setelah melakukan pengisian formulir, mahasiswa melanjutkan pada setiap tahapan yaitu A1, A2 dan A3. Formulir Lembar A1 merupakan formulir yang akan diunduh mahasiswa dan ditandatangani oleh dosen yang bersangkutan kemudian didaftarkan kepada koordinator sebagai awal tahapan penagmbilan skripsi. Formulir A2 merupakan formulir yang akan diunduh mahasiswa dan ditandatangani oleh 2 dosen pembimbing sebagai syarat pendaftaran proposal skripsi. Formulir A3 merupakan formulir yang akan diunduh mahasiswa dan ditandatangani oleh 2 dosen pembimbing sebagai syarat pendaftaran kolokium

\section{Model Dosen}

Dosen berperan sebagai pembimbing dan pembahas skripsi dimana kuotanya dan bidang keahlian untuk topik skripsi sudah ditentukan sehingga dosen hanya dapat memantau status bimbingannya apakah sudah selesai, terhambat atau yang lainnya (Gambar 11). Dalam hal ini dosen diharapkan dapat menjadi motivator dan membantu mahasiswa bimbingannya jika terjadi hambata atau kesulitan. 
Status Pembimbing I

Daftar Mahasiswa Bimbingan

\section{Lihat}

Status Pembimbing II

Daftar Mahasiswa Bimbingan

\section{Lihat}

\section{Gambar 11. Tampilan Beranda Dosen}

\section{Pengujian}

Setelah dilakukan pengujian sistem, maka didapatkan hasil pengujian seperti yang terdapat pada tabel 3.

Tabel 3. Pengujian Pada Web Browser

\begin{tabular}{|c|c|c|c|c|}
\hline No & Browser & Versi & Hasil & Keterangan \\
\hline 1 & $\begin{array}{c}\text { Google } \\
\text { Chrome }\end{array}$ & $\begin{array}{c}79.0 .3945 .117 \text { (Official } \\
\text { Build) (64-bit) }\end{array}$ & Berhasil & $\begin{array}{c}\text { Aplikasi dapat dijalankan sesuai } \\
\text { dengan yang diharapkan }\end{array}$ \\
\hline 2 & $\begin{array}{c}\text { Mozila } \\
\text { Firefox }\end{array}$ & 03.05 .02 & Berhasil & $\begin{array}{c}\text { Aplikasi dapat dijalankan sesuai } \\
\text { dengan yang diharapkan }\end{array}$ \\
\hline 3 & $\begin{array}{c}\text { Internet } \\
\text { Explorer }\end{array}$ & 10 & Berhasil & $\begin{array}{c}\text { Aplikasi dapat dijalankan sesuai } \\
\text { dengan yang diharapkan }\end{array}$ \\
\hline
\end{tabular}

\section{KESIMPULAN}

Berdasarkan penelitian ini, peneliti dapat menyimpulkan bahwa :

1. Sistem manajemen dan input tugas akhir/skripsi di Prodi Teknik Geologi UPN "Veteran" Yogyakarta masih manual dengan sistem tanya jawab dan tatap muka langsung terhadap koordinator yang menimbulkan beberapa kekurangan, antara lain : pembagian kuota dan topik skripsi sesuai dengan kompetensi dosen pembimbing belum merata, sulitnya monitor progres skripsi mahasiswa dan sulitnya mahasiswa menentukan topik dan calon dosen pembimbing.

2. Sistem manajemen dan tugas akhir berbasis website mengakomodir dosen dengan mudah memantau perkembangan bimbingannya dari mana saja, mengakomodir mahasiswa dapat memilih sendiri sesuai topik tanpa harus berkoordinasi dengan koordinator yang tentunya membutuhkan waktu yang cukup lama.

3. Masih adanya kekurangan dalam sistem ini terkait dengan pengolahan data dari admin yang semi manual sehingga perlu koordinasi dengan pihak fakultas untuk meminta data.

4. Kedepannya akan diupayakan untuk terkoneksi langsung dengan data fakultas sehingga tanpa admin input manual

\section{DAFTAR PUSTAKA}

Alatas, H. 2013. Responsive Web Design Dengan PHP \& Bootstrap. Yogyakarta: Lokomedia. Arief, R., 2011, Pemrograman Web Dinamis Menggunakan PHP dan MYSQL, Andi, Yogyakarta. Casciano, Chris. 2010. The CSS Pocket Guide, California: Peachpit Press.

Diki Alfarabi Hadi., 2018. Codeigniter Part 1 : Pengertian dan Cara Menggunakan Codelgniter. Malas Ngoding. https://www.malasngoding.com/pengertian-dan-cara-menggunakancodeigniter/. (Diakses pada 14 Mei 2019)

Fikriansyah., 2017. Apa Itu MySql, Sejarah, dan Fungsinya. TutorialPedia.NET. https://www.tutorialpedia.net/apa-itu-mysql/. (Diakses pada 14 Mei 2019).

Hakim, Lukmanul., 2010. Membangun Web Berbasis PHP dengan Framework Codeigniter. Yogyakarta : Lokomedia. 
Hartono Milawati., 2016. Pengertian, Komponen dan Contoh Use Case Diagram. https://milawatihartono.wordpress.com/2016/03/31/use-case-diagram/. (Diakses pada 14 Mei 2019).

Ilham Falachul Adha., 2019. Pengertian PHP: Pengenalan PHP. SinauWeb.ID. https://sinauweb.id/tutorial/pengenalan-php/. (Diakses pada 14 Mei 2019)

Jundi Alwan., $2017 . \quad$ Kenal Javascript: Perkenalan. Medium. https://medium.com/@jundialwan/kenal-javascript-perkenalan-a952bde1f59e. (Diakses pada 14 Mei 2019).

Nugroho, Bunafit., 2009. Latihan Membuat Aplikasi Web PHP dan MySQL Dengan Dreamweaver. Yogyakarta: Gava Media

Rahmayu, M., 2016. Rancang Bangun Sistem Informasi Pada rumah Sakit Dengan Layanan Intranet Menggunakan Metode Waterfall, Jurnal Evolusi, (4) 2, 2338 - 8161.

Ritonga Pahmi., 2015. Pengertian Unified Modeling Language ( UML) dan Modelnya Menurut Pakar dan Ahli. https://bangpahmi.com/pengertian-unified-modeling-language-uml-danmodelnya-menurut-pakar-dan-ahli/. (Diakses pada 14 Mei 2019).

Sibero, Alexander. 2013. Web Programming Power Pack. Yogyakarta: MediaKom

Uinersitas Negeri Yogyakarta. 2020, Tugas Akhir, https://www.uny.ac.id/akademik/tugas-akhir, diakses 10 Maret 2020. 